\title{
DESLOCATIVIZACIÓN Y ABSTRACCIÓN DIACRÓNICA DE FRASES PREPOSICIONALES CON $A$. EFEGTO DOMINÓ EN UN CAMBIO LÉXICO-SEMÁNTICO
}

\author{
DIACHRONIC DELOCATIVIZATION AND ABSTRACTION \\ OF PREPOSITIONAL PHRASES WITH $A$. \\ DOMINO EFFECT IN A LEXICAL AND SEMANTIC CHANGE
}

\author{
Rodrigo Flores DÁvilla \\ Universidad Nacional Autónoma de México \\ rodrigofloresdavila@gmail.com
}

Resumen: En este artículo se analiza, desde una perspectiva diacrónica, la relación entre dos procesos de cambio léxico-semántico experimentados por frases con la pauta $a+$ frase nominal: deslocativización y abstracción. El principal hallazgo de esta investigación es que, a lo largo de la historia, el significado básico locativo de esta clase de frases disminuyó en beneficio del no locativo; este hecho propició el incremento de frases nominales con carácter abstracto, en perjuicio de las frases nominales con carácter concreto. El interés de estos cambios léxico-semánticos radica en que se cumplieron a modo de "efecto dominó" una primera deslocativización y una subsecuente abstracción.

Palabras clave: preposición $a$; deslocativización; abstracción; cambio léxico-semántico; cambio diacrónico.

Abstract: This paper analyses, from a diachronic perspective, the relation between two lexical and semantic diachronic processes of change in the prepositional phrase consisting of the preposition $a+$ noun: delocativization and abstraction. The main finding of this research is that, throughout the history of Spanish, the basic locative meaning of this sort of phrases decreased in favor of non locative ones. This led to an increase in the amount of abstract nominal phrases, to the detriment of concrete ones. The interest of this lexical and semantic change is that it ocurred as a result of a "domino effect": a first delocativization cleared the way for a subsequent abstraction.

Keywords: preposition $a$; delocativization; abstraction; lexical and semantic change; diachronic change.

Recepción: 27 de octubre de 2016; aceptación: 19 de junio de 2017.

D.R. () 2018. Nueva Revista de Filología Hispánica Licencia Creative Commons Attribution-NonCommercial (CC BY-NC) 4.0 International 
INTRODUCGIÓN*

La frase preposicional encabezada por $a$ (en adelante FP- $a$ ) se caracteriza por haber incrementado de modo significativo, a lo largo de la historia del español, el número de contextos funcionales, argumentales y no argumentales, en los que participa. Efecto y causa de tal ampliación funcional es que la frase nominal, término de la preposición, se alejó progresivamente de los contextos semánticos etimológicos de $a$ y aceptó, en consecuencia, valores afines a las nuevas relaciones gramaticales establecidas. Llaman la atención, de modo particular, la deslocativización y la abstracción experimentadas por el término de la FP- $a$, ya que ambos procesos constituyen un cambio léxico-semántico a modo de "efecto dominó"; esto es, un cambio secuencial en el que un proceso primario sustenta e impulsa el movimiento de uno secundario. De modo específico, la gradual deslocativización de las distribuciones de la FP- $a$ constituyó la base y la causa del subsecuente incremento de abstracción en los términos preposicionales.

Los valores básicos involucrados en el cambio secuencial que experimentó la semántica de la FP- $a$ son dos: uno, el significado etimológico 'locativo directivo télico' de la preposición $a$, y otro, el carácter concreto expresado en el término de esta preposición ${ }^{1}$. Entre ambos significados, locativo y concreto, se establece una relación intrínseca que se sustenta en el hecho de que la naturaleza etimológica locativa de la preposición $a$ se codifica preferentemente con términos concretos, toda vez que una locación se aviene mejor con entidades concretas antes que con entidades abstractas.

Con base en el supuesto anterior, el alejamiento del valor locativo del término de la preposición $a$ se realiza mediante un proceso de deslocativización, que impacta directamente en el carácter concreto de éste y tiene como consecuencia, por tanto, un proceso de abstracción ${ }^{2}$.

* Agradezco a los dictaminadores anónimos la lectura crítica y los comentarios a este texto; sin duda, ayudaron a mejorar el contenido. Mi agradecimiento a Concepción Company por la generosa lectura y las atinadas sugerencias a una versión preliminar de este trabajo. Los errores son, por supuesto, responsabilidad mía.

${ }^{1}$ En este trabajo retomo, desde una nueva perspectiva, datos de dos investigaciones: Flores Dávila 2013 y Company CoMpany y Flores Dávila 2014.

${ }^{2}$ Véase, a este respecto, LuRAGHi 2003, pp. 11-48. 
El proceso de deslocativización de la FP-a, a la luz de los datos de esta investigación, parece haberse producido en diversas fases sucesivas, no excluyentes entre sí: una primera etapa con una amplia documentación de contextos locativos estrictos $(1 a)$; un segundo momento con un notorio incremento de contextos con extensiones semánticas locativas $(1 b)$ y una tercera fase con un aumento de contextos desprovistos de matices locativos (1c).

(1) a. Quitosse de la ciudat de Nazareth, e fue morar a Capharnaum [Mateo, p. 27].

dicho alcalde mayor fue a su casa a embargarle lo que tenía [DLNE, 170, p. 448].

Subieron por las faldas del monte hasta llegar a su milpa [Ángeles, p. 164].

$b$. cuando llegaste junto a ella, ¿no sentiste un olor sabeo, una fragancia aromática y un no sé qué de bueno, que yo no acierto a dalle nombre? [Quijote I, 31].

llegando al Credo... dije: "padeció so el poder de Poncio de Aguirre" [Buscón, I, 1, pp. 84-85].

Y me ha venido a la memoria otro artista del No [Bartleby, p. 59].

$c$. propuso de hacerse armar caballero del primero que topase, a imitación de otros muchos que así lo hicieron [Quijote I, 34]. Me reí a solas [Bartleby, p. 12].

Al menos, eso es lo que la mujer acostumbraba explicar [Vuelo, p. 13].

La abstracción del término de la FP- $a$, por su parte, se efectuó mediante el paso de términos preposicionales de carácter concreto $(2 a)$ a términos preposicionales de naturaleza abstracta $(2 b)^{3}$.

(2) a. Et yo dixe verdat et mostrarélo por prueba, et díxelo al rey, et conplí el omenaje que le devía [Calila, p. 187].

Yo, viendo que era batalla nabal y que no se había de hacer a caballo, comencé a apearme [Buscón, I, 1, p. 87].

Es imperioso volver al departamento que odia porque allí, junto a la cama que quisiera destruir e incendiar, está el teléfono [Vuelo, p. 267].

$b$. et mejor es de ser justiçiado en este mundo que ir a la pena durable en el otro [Calila, p. 190].

${ }^{3}$ Si bien los contrastes locativo vs. no locativo y concreto vs. abstracto forman sendos continuum, ya que los datos del corpus expresan múltiples valores intermedios entre una y otra característica del contraste, para los fines operativos de este trabajo, distingo tales dicotomías con el propósito de no atomizar el análisis. 
Para dar mayores avisos de legalidad a la trapisonda, Cárcamo lo registró en la prisión con su nombre cristiano [Ángeles, p. 479].

Le ha bastado con enfrentarla a su fragilidad, a su pequeñez, a su insalvable dependencia del hombre que aún la ama [Vuelo, p. 271].

Es necesario señalar, en este punto, que el contraste concreto/ abstracto entraña no pocas dificultades, en tanto que la afiliación de ciertos nombres en una u otra de estas categorías resulta problemática. Sobresale particularmente el caso de los nombres abstractos, ya que los criterios para determinar los límites de la categoría son difusos -por ejemplo, para los nombres en contextos de interpretaciones genéricas o irreales (cf. I. Bosque 1999, t. 1, §1.5)-, o bien porque suelen explicarse en términos de otros rasgos semánticos, tales como contable/ masa ${ }^{4}$. Debido a la caracterización poco delimitada de la etiqueta abstracto, en las últimas décadas se ha extendido la polémica sobre la pertinencia de emplear esta clasificación en el análisis gramatical (RAE-ASALE 2009, §12.1j). Así, por ejemplo, la última edición de la gramática académica señala que la tendencia ante tal dificultad es caracterizar los sustantivos abstractos con base en "propiedades sintácticas o semánticas más objetivas" (\$12.1k).

A pesar del panorama expuesto arriba, he considerado que, a la luz de los datos, las etiquetas concreto y abstracto se acercan más a los criterios empleados en el análisis de este trabajo. Así pues, he incluido bajo la etiqueta concreto aquellos nombres caracterizados por aludir a seres u objetos con existencia real, material o física ${ }^{5}$, como los ejemplificados en $(2 a)$; en cambio,

${ }^{4}$ Aunque los rasgos concreto/ abstracto parecen no ser definitorios en la caracterización semántica de los nombres (BosQUe 1999, t. 1, §1.6.2), considero que, para los fines de este trabajo, el contraste contable/ no contable (masa), propuesto en obras de índole similar, no siempre resulta determinante, ya que dicho análisis es también susceptible de subcategorización: contable abstracto ( problema, anhelo, deseo, etc.), contable concreto (mesa, hoja, botella), no contable concreto (harina, arena, aceite), no contable abstracto (fe, paciencia, música). Como puede verse, el par contable/ no contable no resuelve del todo las dificultades que generan las nociones concreto/ abstracto. De hecho, tanto contables abstractos como no contables abstractos siguen teniendo en común la inmaterialidad del referente, que es el criterio bajo el que se analizan los ejemplos de este trabajo.

${ }^{5}$ Sigo, grosso modo, las definiciones propuestas por la gramática académica, §12.1i. 
bajo la etiqueta abstracto he incluido los nombres carentes de realidad material, como acciones, procesos, cualidades, etc., tal y como se ve en los ejemplos de (2b). Emplearé, por tanto, estas denominaciones como etiquetas meramente operativas.

Los datos de este trabajo están relacionados de forma directa con dos aspectos teóricos fundamentales para el cambio lingüístico: por un lado, se asocian con el hecho bien conocido de que en los procesos de cambio los contextos innovadores se alejan progresivamente del significado básico etimológico, a la vez que mantienen durante siglos parte de esos valores ${ }^{6}$. Por otro, los datos se vinculan, asimismo, con la tendencia generalizada de las formas lingüísticas a la abstracción, tal y como sucede en los procesos metafóricos o metonímicos propuestos en diversas gramaticalizaciones, en las que se documenta un camino que va de una semántica concreta a una semántica abstracta ${ }^{7}$.

Por lo que toca al primer aspecto teórico, el cambio léxico-semántico sufrido por la FP- $a$ confirma el distanciamiento previsto entre los contextos innovadores y el significado etimológico, aunque, como es natural, tales innovaciones tienen antecedentes en la lengua, puesto que se trata de modificaciones y no de creaciones ex novo (cf. Company 2003a). La FP- $a$ se alejó cada vez más del valor etimológico locativo de la preposición $a$ y amplió, en consecuencia, sus contextos innovadores. Pese a estos cambios, la FP- $a$ ha mantenido durante siglos el carácter locativo básico contenido en la etimología de $a^{8}$. En cuanto al segundo aspecto, el término de la FP- $a$ sigue el camino esperado de abstracción, ya que, a lo largo de la historia de la lengua española, los términos de $a$ se han distanciado de la

${ }^{6}$ La implicación de esta postura teórica es que las estructuras innovadoras se incorporan primero en contextos altamente propicios para su inserción y, consecuentemente, avanzan a los menos favorables o más reacios; a este respecto, véanse KROCH 1989 y COMPANy 2003a.

7 Son muchos los autores que han estudiado los procesos metafóricos de cambio; basten como ejemplo los trabajos de LAKoff \& Johnson 1980, p. 113; Claudi \& Heine 1986, p. 299; Heine, Claudi \& Hünnemeyer 1991, p. 45 ; y Hopper \& Traugott 2003, p. 84.

8 En esta investigación, considero que el valor locativo de la preposición $a$ es persistente incluso en aquellos contextos en los que éste no es recuperable formalmente, por lo menos no desde una perspectiva sincrónica y léxica. Mi postura es que tales contextos son, por tanto, el resultado de procesos de cambio diacrónico favorecidos por el significado básico y las relaciones primarias que se establecen a partir del valor locativo. 
condición semántica de mayor concreción que presentaba esta preposición en sus orígenes (Flores 2013, p. 70).

Si bien en la caracterización presentada hasta ahora subyace la idea de que la FP- $a$ posee valores léxico-semánticos inherentes únicamente a la preposición y a su término, doy por aceptado que la significación completa de la FP- $a$ está siempre constreñida al contexto sintáctico en el que se hace efectiva la frase. Para el análisis semántico de la FP- $a$ en este trabajo, he tomado en cuenta siempre el vínculo establecido entre los tres elementos que integran la relación gramatical o funcional: el elemento rector, la preposición y el elemento regido. Cada uno de estos componentes posee condiciones semánticas propias a su vez, empero todos están intrínsecamente condicionados por las relaciones funcionales, puesto que éstas restringen o activan los valores léxico-semánticos de cada elemento ${ }^{9}$.

De este modo, por ejemplo, la selección de la preposición que encabeza el complemento locativo de un verbo de movimiento como ir estará constreñida por los rasgos particulares del contexto de la construcción: si el verbo se emplea en un contexto de movimiento directivo, la FP estará encabezada por la preposición $a$, "voy $a$ Santaella"; en cambio, si el contexto es de movimiento directivo indiferente a la dirección, el verbo preferirá una FP con la preposición por, "voy por Santaella" (cf. García-Miguel 1995, pp. 174-175, y Crego García 2000, pp. 102-116). De igual forma, la selección del término de la preposición $a$ en función de objeto directo (en adelante OD) presentará preferencias en cuanto a las características léxicas del núcleo de la frase nominal (en adelante FN): mejor animados, "veo a los niños corriendo", que inanimados, "la mayoría de la gente ve a las playas desde una óptica vacacionista" ${ }^{0}$. En resumidas cuentas, la postura que tomo para el análisis intenta conciliar, en la medida de lo posible, el vínculo entre el sig-

${ }^{9}$ Los datos que conforman el corpus de esta investigación han sido tratados tanto desde una semántica particular, para cada componente de la FP- $a$, como desde una semántica de construcción, es decir, con atención a los valores añadidos en cada contexto funcional. Es oportuno señalar que existen otras posturas teóricas en las que se considera, por ejemplo, que los valores expresados mediante las preposiciones locativas están seleccionados por el verbo; téngase por caso GEHRKE 2008 y BosQUE 2015.

10 Este ejemplo procede del Diario de Yucatán (01-09-1996, México) y está tomado del banco de datos Corpus de Referencia del Español Actual (CREA), de la Real Academia Española, disponible en http:/ / www.rae.es. 
nificado léxico de las preposiciones y la función sintáctica en que participan.

Además de la presente introducción, he organizado este trabajo en siete apartados generales. En el segundo hago la descripción del corpus base de esta investigación. En el tercero expongo un breve estado de la cuestión sobre los temas que han suscitado mayor interés en la bibliografía con respecto al cambio léxico-semántico de la FP- $a$. En el cuarto planteo la hipótesis que guía el análisis de los datos. El quinto, y más extenso, está integrado por dos subapartados relativos al proceso de deslocativización de la FP-a: en el primero analizo el carácter locativo o no locativo de los datos que conforman el corpus; en el segundo restrinjo el análisis únicamente a las FP- $a$ con función de complemento circunstancial. En el sexto apartado presento el estudio del proceso de abstracción; en esta sección contrasto los valores concreto y abstracto de término de la FP- $a$. En el séptimo pongo a discusión los resultados obtenidos en las variables analizadas y presento una descripción general del cambio secuencial a modo de "efecto dominó". Presento, finalmente, unas conclusiones en el octavo apartado.

\section{CORPUS Y METODOLOGÍA}

El corpus base de esta investigación está estructurado diacrónicamente en tres cortes cronológicos: segunda mitad del siglo XIII, segunda mitad del siglo XVII y primera década del siglo XXI. La elección del siglo XIII como punto de partida se justifica porque es a partir de este período cuando hay un mayor número de textos, y éstos gozan de una importante diversidad temática, por lo que es posible documentar de mejor manera todas las distribuciones posibles del objeto de estudio. El siguiente corte cronológico, siglo XvII, fue elegido por constituir una etapa especialmente provechosa para el cambio lingüístico del español; por un lado, hay constancia de estandarización en el sistema gramatical y, por otro, se producen múltiples cambios de reestructuración en muchos de los fenómenos estudiados ${ }^{11}$. Por último, la decisión de elegir el siglo xxi como tercer corte cronológico se hizo para establecer un intervalo similar al

11 Para mayor detalle sobre el tratamiento del siglo xvir en estudios de cambio lingüístico, véase COMPANY 2014. 
que hay entre el primero y el segundo, cercano a 400 años. La comparación de estas tres etapas permite, además, dar cuenta del estado y raigambre de los procesos de cambio sufridos por la semántica de la FP- $a$.

Los textos que conforman el corpus corresponden a once obras: cuatro para el siglo XIII, tres para el XVII y cuatro para el xxi ${ }^{12}$. Para evitar la posibilidad de que se prescinda de la preposición $a$ por razones de métrica, todos los escritos utilizados son en prosa. Cabe señalar que la selección de los documentos que conforman el corpus se basó, primero, en la fiabilidad de los textos, de ahí que se hayan empleado, en su mayoría, ediciones críticas; segundo, en la diversidad textual, de modo que, en la medida de lo posible, en cada corte cronológico fueron incluidas obras historiográficas, textos sapienciales, novelas y textos jurídicos; $y$, tercero, puesto que esta investigación pretende dar cuenta del español general, a partir del segundo corte cronológico, siglo XVII, existe diversificación dialectal. Además de los textos procedentes de España, se integraron obras de México en el segundo corte cronológico, y de Argentina y México en el tercero.

Con el propósito de guardar cierta comparabilidad cuantitativa entre los diferentes cortes cronológicos, he realizado un muestreo al azar sobre un universo fijo de palabras para cada período: 20000 palabras para el primer y tercer corte cronológicos, respectivamente, y 15000 para el segundo; esto es, 5000 palabras por texto. Los parámetros utilizados para determinar el universo de palabras tuvieron como objetivo otorgar a todo el texto la posibilidad de ser analizado, de modo que se incluyó en el corpus toda aquella FP- $a$ que cumpliera con los requisitos formales y estuviera dentro de las 5000 palabras seleccionadas en cada obra.

Por lo que toca a la metodología empleada en la selección y análisis de los ejemplos, se incluyeron, desde una perspectiva formal, todas aquellas FP- $a$ que siguieran el esquema $a+\mathrm{FN}$, ya que se trata de la pauta más recurrente en las frases encabeza-

12 El menor número de textos empleados en el siglo xviI responde al hecho de que en ese período se eleva significativamente la documentación de FP- $a$. La reducción en el número de obras tiene como objetivo equilibrar la muestra cuantitativa con respecto a los otros dos cortes cronológicos. Para los títulos y ediciones de las obras que conforman el corpus, véase el "Anexo" al final del estudio. 
das mediante la preposición $a^{13}$. El término de las FP- $a$ incluidas en el corpus podía ser una FN con un núcleo sustantivo, propio o común: "voy de Puerma a Córdoba", "recurre a un aboga$d o$ ", "nos vemos a las tres"; o bien un pronombre: "se parece $a$ mí", "arresten a ése", "pese a ello". Además, la FN, término de la preposición $a$, podía constituirse mediante una frase simple, esto es, con sólo el núcleo léxico, sin determinante o modificador alguno: "gracias a Javier", "díselo a papâ", "regresa a casa"; o bien una frase compleja, esto es, con los modificadores propios de su clase, determinantes o modificadores: "se unió a la enorme celebración", "llevaba un vestido muy a lo francés"14.

Cabe señalar que la distribución funcional y/o semántica de la FP- $a$ no constituyó un filtro en la selección de datos, puesto que fueron incluidas en el corpus frases en cualquiera de sus contextos funcionales o semánticos. Tampoco se consideró un filtro la naturaleza del elemento rector de la FP- $a$, ya que incluí frases con introductores de cualquier clase gramatical: verbo, "corría a toda prisa"; nominal, "horror al agua"; adjetivo, "traducido al inglés"; adverbio, "frente a la casa". Fueron incluidas, asimismo, FP- $a$ carentes del elemento rector: "; a la chingada!”, ";al agua, patos!", aunque, por lo general, en el corpus el elemento rector de las FP- $a$ es un verbo. La razón de tales decisiones metodológicas se basa en el hecho de que el corpus tenía como propósito analizar, precisamente, todas las distribuciones sintácticas y semánticas posibles en las que la preposición $a$ con una FN como término ha participado a lo largo de la historia del español.

El resultado cuantitativo general de la búsqueda en el corpus fue de $1390 \mathrm{FP}-a$. La frecuencia de FP- $a$ por siglo se distribuye de la siguiente manera: 442 en el siglo XIII, 427 en el XVII

13 Company y Flores (2014, pp. 1245-1246) señalan la preferencia de la FP- $a$ por términos nominales. En su investigación, $80 \%$ de los datos del corpus siguen esta pauta, frente a $20 \%$ de FP- $a$ con cualquier otro tipo de término. Por tanto, en el presente trabajo quedaron excluidas las FP- $a$ con términos de otra naturaleza gramatical, tales como infinitivos, "salimos a pasear"; adjetivos, "más bien tiraba a malo"; adverbios, "que el dolor no vaya a más"; otra preposición, "vamos a por agua", y oraciones introducidas por la conjunción que, "fui a que me cortaran el cabello", etcétera.

${ }^{14} \mathrm{Si}$ bien otros autores emplean las etiquetas escueta y no escueta para referirse a la estructura interna de la FN (véase, por ejemplo, Bosque 1996), en esta investigación utilizo la etiqueta simple para referirme exclusivamente a las FN carentes de llenado léxico en ambos márgenes, por lo que las FN con determinante están incluidas en el grupo de frases complejas. 
y 521 en el Xxi. Una vez establecido el corpus, se estudiaron los datos desde diversas perspectivas formales, funcionales y semánticas. Así, por ejemplo, analicé la estructura interna de cada una de las FN registradas, sus rasgos léxico-semánticos, su función sintáctica, la naturaleza semántica del verbo rector, etc. Este trabajo presta atención, de modo específico, a los resultados obtenidos en cuanto a la naturaleza locativa/ no locativa y concreta/ abstracta de la FN, término de la preposición $a$.

Es necesario señalar que el número de datos estudiados en cada uno de los apartados de este trabajo varía, puesto que corresponde a contextos semánticos y funcionales diferentes. El universo de FP- $a$ analizadas en el primer subapartado de "Análisis léxico-semántico del carácter locativo en la FP- $a$ " incluye el total del corpus: $1390 \mathrm{FP}-a$; en el segundo subapartado analizo las FP- $a$ en función de complemento directo (en adelante CC): 530; y, finalmente, el apartado "Análisis léxico-semántico del contraste concreto vs. abstracto..." está conformado por las FP- $a$ en cuyo término se codifica un nombre común: 1094 FP- $a$. Para mayor claridad, los criterios empleados para el análisis de cada variable están especificados y ejemplificados en los apartados correspondientes.

\section{BREVE ESTADO DE LA CUESTIÓN}

El estudio de la preposición $a$ ha sido tema recurrente en las gramáticas de referencia de la lengua española y en múltiples trabajos especializados. En ambos casos, las obras suelen centrarse, por un lado, en el análisis de los contextos funcionales en los que participa esta preposición y, por otro, en la descripción de sus valores semánticos ${ }^{15}$. Sin embargo, a pesar del gran interés que ha suscitado el incremento diacrónico funcional y contextual de la FP- $a$, son escasos los trabajos que orientan su análisis hacia los procesos de cambio léxico-semántico experimentados por la preposición $a$ y su término; son aún más escasos aquellos que abordan la deslocativización y la abstracción. En este breve estado de la cuestión expongo, precisamente, los

15 Los temas que en perspectiva diacrónica suscitan mayor interés entre los estudiosos son los procesos de cambio experimentados por la preposición $a$ en las funciones de objeto indirecto y objeto directo. Para un estado de la cuestión más completo a este respecto, véase COMPANy y Flores 2014, pp. 1225-1228. 
aspectos más llamativos en cuanto a tales procesos de cambio. Comienzo por abordar el tema de la locación en la FP- $a$ y el proceso de deslocativización, y finalizo con la información recabada en cuanto al carácter concreto y el correspondiente proceso de abstracción.

La locación constituye, como es sabido, uno de los dominios cognitivos básicos del pensamiento y del lenguaje humanos, puesto que se trata de una de las relaciones espaciales primordiales para la codificación de la realidad. Para la tipología lingüística la locación conforma, en efecto, una de las relaciones básicas expresadas en las lenguas, ya que mediante este dominio los hablantes sitúan o posicionan, con respecto de sí mismos, a otros hablantes, objetos o eventos ${ }^{16}$. Sobresale, de modo particular, la categoría preposición, ya que se trata de una parcela de la gramática especialmente prolífica en cuanto a la expresión de relaciones locativas ${ }^{17}$.

El valor locativo característico de la FP- $a$ tiene sustento en su antecesora, la preposición latina $a d$, que incluía ya entre sus múltiples valores el de ubicación locativa, además de ser empleada en otros muchos contextos espaciales y no espaciales: dirección, tiempo, beneficiario, causa-fin, modo, entre otros (cf. Glare 2012, s.v. $a d$ ). A este respecto, Baños Baños (2009, pp. 299-347) señala que $a d$ participaba, por ejemplo, en contextos espaciales de "orden vertical" ( $3 a)$, en cuyo caso $a d+$ acusativo implicaba un valor de orientación hacia un referente, pero sin que se diera necesariamente un contacto. De igual modo, $a d+a c u-$ sativo se empleaba en contextos de dirección en los que el verbo de movimiento no expresaba per se el valor directivo (3b). Este último caso resulta sumamente llamativo, puesto que el autor señala que el sustantivo término de la preposición ad podía expresarse, además de con un término locativo, con "términos no estrictamente espaciales", tales como las entidades humanas (4a) o incluso en extensiones metafóricas y/o metonímicas que limitaban con un sentido de finalidad (4b), tal como sucede en español con la preposición $a$.

16 El estudio de los correlatos establecidos entre los procesos cognitivos espaciales y su codificación lingüística puede verse de manera pormenorizada en Levinson \& WiLkins 2006.

17 Para un análisis detallado del concepto locación, desde las perspectivas cognitiva, tipológica y preposicional, véanse, respectivamente, LEVINSON 2003, pp. 6-14, STOLz 1992, p. 30, y LuRAGHi 2003, pp. 20-27. 
(3) a. Caesar... ad oppidum constitit iuxtaque murum castra posuit [Caes. civ. 1, 16, 3, apud Baños 2009, p. 321].

'César... se paró a las puertas de la villa y estableció el campamento pegado a sus murallas'.

b. nauigabit igitur... et ad Italiam accedet [Cic. Att. 10, 8, 4, apud Baños 2009, p. 323].

'así que navegará y... se acercará a Italia'.

(4) a. postridie... Germani... ad eum in castra uenerunt [Caes. Gall. 4, 13, 4, apud Baños 2009, p. 324].

'al día siguiente... los germanos se presentaron ante César en su campamento'.

b. Syphacem... prodit in castra Romana ad conloquium uenisse [Liv. 30, 3, 6, apud Baños 2009, p. 324].

'cuenta que... Sífax fue al campamento romano para la entrevista'.

Con base en los supuestos anteriores, es posible reconocer que los valores expresados por ad en sus diversos contextos -y los procesos que venían sucediendo en latín-constituyeron los cimientos locativos de la FP- $a$ y también el germen de los cambios que la preposición $a$ y su término han sufrido a lo largo de la historia. La naturaleza locativa de la preposición $a$ ha sido, sin duda, uno de sus rasgos caracterizadores, y tanto gramáticas como trabajos especializados han prestado atención a ese valor ${ }^{18}$. Las apreciaciones de los estudiosos son múltiples y se distinguen por otorgar o negar el valor léxico de $a$, empero se suele aceptar que esta preposición posee valores locativos.

En perspectiva diacrónica, el cambio experimentado por la FP- $a$, en cuanto al valor locativo, ha sido escasamente tratado, a pesar de constituir un significado caracterizador de la preposición $a$ y de estar presente en diverso grado en muchas de las funciones en las que participa. Uno de los trabajos que, en últimas fechas, ha tratado la diacronía del carácter locativo de la FP- $a$ es el de Company y Flores (2004, pp. 1320-1321), quienes dan cuenta, por un lado, de la persistencia diacrónica del valor locativo en muy diversos contextos funcionales y semánticos y, por otro, muestran que, no obstante el arraigo del carácter locativo de la FP- $a$, éste se ha debilitado a lo largo de los siglos. Una de las aportaciones más interesantes en el trabajo de

18 Hanssen 1913, §688; Alcina Franch y Blecua 1975, §6.2.5; Alarcos Llorach 2004, §289; RAE-ASALE 2009, §29.4.3a; PotTIER 1955, pp. 347-354; Trujillo 1971, p. 271, y García-Miguel 1995, p. 98. 
Company y Flores es, a mi parecer, que el carácter locativo de la FP- $a$ cedió su espacio semántico mediante extensiones contextuales en un proceso de cambio que va de contextos locativos $>$ contextos humano/ temporales $>$ contextos modales. Esta evaluación del fenómeno constituye la base del análisis que presento en el apartado "Análisis léxico-semántico del carácter locativo en la FP- $a$ ”.

En cuanto al carácter concreto de las preposiciones, estudiosos del latín han señalado que éstas originalmente establecían relaciones semánticas concretas, puesto que aludían, en primer lugar, a entidades espaciales ${ }^{19}$. Asimismo, se ha indicado que a lo largo de la historia del latín, los contextos del término preposicional se flexibilizaron y comenzaron a codificar entidades de naturaleza más abstracta (Bassols de Climent 1956, t. 2, pp. 238-239). Con independencia de tales afirmaciones, la información lexicográfica que registran los diccionarios latinos indica que la participación de las preposiciones no se restringía de ningún modo a los contextos espaciales-concretos; así, por ejemplo, el Oxford Latin dictionary (Glare 2012, s.v. ad) asigna, para el caso de la preposición latina $a d$, hasta 46 acepciones, distribuidas en siete diferentes clases, dentro de las cuales existen valores no espaciales y no concretos, tales como adición o incremento, respuesta, comparación o norma, función, propósito o resulta$d o$. Al igual que en la lengua madre, es posible observar que las preposiciones españolas se avienen bien con términos preposicionales que codifican el valor concreto; es el caso de la FP- $a$. De igual modo, se hace evidente que los términos preposicionales gozan de mayor flexibilidad a favor de expresiones de carácter $a_{b s t r a c t o}{ }^{20}$, tal como ya sucedía en latín.

Finalmente, el contraste concreto vs. abstracto codificado en los nombres comunes término de la FP- $a$ ha sido analizado por Company y Flores (2004, pp. 1272-1274), quienes señalan, por un lado, que los términos preposicionales que codifica el primero de estos valores, el concreto, son los preferidos por la FP- $a$, y confirman, por otro, que a lo largo de la historia del español, la FP- $a$ se flexibilizó ante términos comunes abstractos. Para estos autores, el proceso general de abstracción de la preposición

19 Cf. Kühner und Stegmann 1914, pp. 488-490, apud Baños Baños 2009, p. 312.

${ }^{20}$ Para una caracterización detallada de la semántica de las preposiciones en español, véase Morera Pérez 1988. 
$a$ está reflejado en el cambio concreto $>$ abstracto experimentado por los nombres comunes del corpus. Confirman este hecho otros cambios registrados en diversos contextos funcionales y semánticos; por ejemplo, el decremento de términos locativos a favor de términos temporales y modales o bien la inclusión en la gramática española de múltiples usos discursivos codificados mediante una FP- $a$, empleados con un significado procedimental, a propósito, al contrario, al menos, al respecto, entre muchos otros.

\section{Hipótesis}

La hipótesis general que guía este trabajo propone que la semántica básica de la FP- $a$ ha sufrido dos procesos diacrónicos de cambio, uno motivado o respaldado por el otro a modo de "efecto dominó". El primer cambio está relacionado con el valor locativo de la FP-a y el segundo con el carácter concreto del término preposicional; se trata de un proceso de deslocativización y un proceso de abstracción, respectivamente. El cambio general consistió en una primera deslocativización de la FP-a y en una subsecuente abstracción del término preposicional. El "efecto dominó" fue posible ya que estos procesos de cambio sucedieron de modo secuencial en el eje diacrónico: el proceso primario, la deslocativización de la FP-a, sustentó e impulsó el movimiento del proceso secundario, la abstracción de la FP- $a^{21}$.

Con esta hipótesis se espera, en primer lugar, que el valor etimológico locativo mantenga cierta estabilidad o continuidad diacrónica, puesto que se trata del valor semántico que dará sustento a los contextos innovadores -extensiones locativas y no locativas- y porque el comportamiento habitual en los procesos de cambio suele presentar tanto continuidades como discontinuidades. Con base en el supuesto anterior, esta hipótesis espera que en el primer corte cronológico haya una menor concentración de FP- $a$ de carácter no locativo, y que en el segundo y tercer cortes cronológicos los casos de naturaleza no locativa se hayan incrementado. La hipótesis espera también

${ }^{21}$ El proceso de cambio a modo de "efecto dominó" puede equipararse con los cambios conocidos como cadena de tracción o cadena de empuje, propuestos por Martinet (1970). No obstante, en el caso de la deslocativización y de la abstracción no existe una relación intraparadigmática, como formula este autor. 
que la FP- $a$ en función de complemento locativo ceda espacio, diacrónicamente, a otros tipos semánticos de complementos, por ejemplo de tiempo o de modo. Con esta hipótesis se espera, por último, que el carácter concreto de la FP- $a$ se documente con mayor frecuencia en el primer corte cronológico y que se modifique en el segundo y tercer cortes a favor de contextos abstractos, hecho que comprobaría que este último cambio ha sido vehiculado por el proceso de deslocativización.

\section{ANÁlisis LÉXICO-SEMÁNTICO DEL CARÁCTER LOCATIVO EN LA FP- $A$}

En este apartado presento los resultados del análisis léxicosemántico con respecto a la naturaleza locativa de la FP- $a$ y expongo la información resultante con respecto al proceso de deslocativización, primero para la generalidad de FP-a y luego, de modo particular, para la FP- $a$ en función de complemento locativo y CC.

\section{La naturaleza locativa general de la FP-a}

Uno de los valores definitorios de la FP- $a$, como he venido señalando a lo largo de este artículo, es el carácter locativo persistente en los diversos contextos funcionales en los que esta frase participa. La semántica locativa de la FN término de la preposición a puede observase, en efecto, tanto en los usos etimológicos que han pervivido diacrónicamente -en cuyo caso se expresa por lo general mediante una locación estricta-, como en los contextos innovadores adquiridos a lo largo de la historia del español -en cuyo caso se codifica preferentemente mediante locaciones no estrictas. La persistencia en la semántica de la FP- $a$ se explica gracias a la reinterpretación metafórica o metonímica del significado básico 'directivo locativo télico' de la preposición $a$. En este aparatado analizo, en primer lugar, la distribución de la FP- $a$ en cuanto a su carácter locativo o no locativo y, en segundo lugar, examino de modo más detallado tal naturaleza léxico-semántica mediante una subclasificación basada en una escala de locatividad.

En cuanto al primer análisis, los datos del corpus indican una primera escisión: por un lado, se documentan FP- $a$ 
caracterizadas por expresar un significado locativo estricto y, por otro, FP- $a$ con un valor locativo no estricto. En el primer tipo se incluyen aquellas FP- $a$ que aluden a una porción concreta y delimitada del espacio físico, tal como puede verse en los ejemplos de $(5 a)$. En el segundo tipo se incluyen las FP- $a$ en las que no se hace referencia a una porción estricta de espacio per se, sino que aluden a extensiones de la locación, por ejemplo un referente humano que no es propiamente un lugar, pero que al ocupar uno adquiere valor locativo $(5 b)$.

(5) a. tomó su lanza y por la puerta falsa de un corral salió al campo [Quijote I, 34].

Llegamos a la calle de la Mar [Buscón, III, 10, p. 255].

Dicen que se aparece en los velorios para quitarles los santos óleos a los difuntos y encaminar sus almas al Mictlán [Ángeles, p. 32].

$b$. cuando llegaba a mínotisia de alguna presea que me urtaba el padre... [DLNE, 162, p. 420].

al anochecer, su rocín y él se hallaron cansados [Quijote I, 2, p. 36].

A intervalos caprichosos, movía el dial, y hablaba con un tono que, desde lejos, parecía afiebrado, incrédulo [Vuelo, p. 124].

El comportamiento de la FP- $a$ en cuanto al carácter locativo de la frase se muestra en el Cuadro 1, el cual deja ver además información general de dos tipos: por un lado, se hace evidente la notoria estabilidad diacrónica para ambas clases de FP- $a$, ya que no existen cambios diacrónicos significativos y, por otro, los datos indican la preferencia general en la codificación de locaciones no estrictas.

\section{CuAdro 1}

Carácter locativo de la FP-a: locativo estricto vs. locativo no estricto

\begin{tabular}{lll}
\hline & Locativo estricto & Locativo no estricto \\
\hline XIII & $21 \%(94 / 442)$ & $79 \%(348 / 442)$ \\
XVII & $25 \%(105 / 427)$ & $75 \%(322 / 427)$ \\
XXI & $21 \%(108 / 521)$ & $79 \%(413 / 521)$ \\
TotAL & $22 \%(307 / 1390)$ & $78 \%(1083 / 1390)$ \\
\hline
\end{tabular}


En cuanto a la primera información, puede observarse la persistencia del valor locativo estricto, a pesar del gran número de casos de FP- $a$ con locaciones no estrictas. Este hecho confirma que la naturaleza locativa de la FP- $a$ está bien asentada desde muy antiguo y que la pervivencia de este valor se debe al estatus de significado básico que posee. Por lo que respecta a la preferencia general de FP- $a$, el corpus muestra una predilección sostenida por aquellos contextos de carácter locativo no estricto: $78 \%$ en total frente al número de casos registrados de FP- $a$ con el valor locativo estricto: $22 \%$ en total. Si bien los casos de construcciones para locativo estricto parecen escasos, es necesario señalar que se trata de FP- $a$ que cumplen, por lo general, con la función de complemento de lugar (véase infra "El valor locativo en las FP- $a$ en función de complemento locativo y complemento circunstancial"), en cuyo caso se trata de construcciones que han mantenido diacrónicamente el valor básico de la FP- $a$. En otras palabras, casi una cuarta parte del corpus ha conservado de modo riguroso el significado etimológico expresado desde sus inicios por la preposición $a$. Por su parte, la preferencia de las FP- $a$ por contextos de locatividad no estricta es, en cierto modo, previsible, ya que dentro del grupo locativo no estricto se incluye un número considerable y heterogéneo de contextos funcionales que presenta otros valores semánticos, con mayor o menor afinidad al carácter locativo.

En perspectiva diacrónica, puede verse en el Cuadro 1 un mínimo aumento de FP- $a$ con carácter locativo estricto entre el siglo XIII y el siglo XVII: $21 \%>25 \%$; tal incremento se dio a expensas de los locativos no estrictos, que en los mismos períodos disminuyó: $79 \%>75 \%$. En el siglo Xxi, la frecuencia de uso tanto de la FP- $a$ de carácter locativo estricto como de las FP- $a$ con una naturaleza locativa no estricta regresó exactamente al mismo porcentaje registrado en el primer corte cronológico: $21 \%$ y $79 \%$, respectivamente.

Con independencia de la aparente estabilidad de las FP- $a$ de naturaleza locativa estricta y no estricta, así como la preferencia contundente por este último tipo de frases, una nueva clasificación de los datos pone de manifiesto información detallada con respecto a los cambios léxico-semánticos experimentados por la FP- $a$ (véase infra el Cuadro 2). Para este nuevo análisis el corpus está organizado en tres grupos. El primero, bajo la etiqueta de locativo, corresponde, al igual que en el análisis previo, a las FP- $a$ que hacen referencia a una porción estricta de espacio 
físico, como en los ejemplos de $(5 a)$. El segundo grupo, bajo la etiqueta de extensión locativa, comprende los casos de FP- $a$ en los que el término preposicional puede explicarse como una extensión metafórica o metonímica del significado básico locativo; estos casos constituyen reelaboraciones en las que el hablante pasa de focalizar la totalidad del espacio físico a focalizar alguno de los elementos que intervienen o se relacionan con éste. Se incluyen en este segundo grupo dos diferentes tipos de frases: el primer tipo corresponde a las FP- $a$ que aluden a una entidad humana, tal como se observa en los ejemplos de $(6)^{22}$, que, como es bien sabido, corresponde a una extensión de la locación, puesto que ocupa inherentemente un lugar en el espacio y por ello puede constituir en sí misma una meta directiva ${ }^{23}$; el segundo tipo atañe a las FP- $a$ en que se expresa o se alude a un término temporal (7), que puede ser interpretado igualmente como una extensión de la locación, en cuyo caso el tiempo se codifica en términos del espacio ${ }^{24}$. En el tercer y último grupo, se incluyen bajo la etiqueta de no locativa las FP- $a$ en que los términos preposicionales expresan principalmente maneras o modos (8); se trata del grupo más alejado del valor etimológico de $a$, en cuanto que las extensiones semánticas de las que proceden no se originan, en principio, del valor locativo de la preposición, sino de otro valor secundario. No obstante, como he venido señalando desde el inicio de este trabajo, el significado básico puede recuperarse incluso en casos como los que contiene este último grupo.

22 El valor locativo expresado en entidades humanas está codificado en los complementos de lugar no argumentales, así como en contextos argumentales, por ejemplo, en las funciones de objeto directo y de objeto indirecto; este último se reinterpreta como meta última de la transitividad. Véase, a este respecto, Company 2003. En cuanto a la relación entre el significado léxico locativo de las preposiciones, reflejado posteriormente en un significado gramatical, véase Kuteva \& SinHa 1994.

${ }^{23}$ En este grupo de FP- $a$ se incluyen todos los casos con término humano, sin importar la función sintáctica que éste cumpla; esto es, además de los humanos codificados como meta de un verbo de movimiento, en esta categoría se incluyen los casos de OD humanos, OI humanos, etcétera.

${ }^{24}$ Haspelmath (1997) expone casos de este proceso en cincuenta y tres lenguas. El autor documenta casos para la preposición $a$ y para otras preposiciones del español. 
(6) a. fuese luego el siervo della a una mançeba que tenía el pintor [Calila, p. 185].

b. sobre eso pienso ir al Papa y gastar lo que tengo [Buscón, II, 3, p. 149].

c. Esto es lo que me ha llevado esta mañana a la osadía de enviarle una carta a París a Robert Derain [Bartleby, p. 18].

(7) a. E quel es el logar o á el mucho oro, segund dize otrossí Moisén, e es a nueve días del monte Oreb [GEI, 2, p. 861].

b. Al atardecer, fuimos a su estudio [Bartleby, p. 163].

$c$. estuve trabajando con la señora gloria rodríguez de la torre..., de nueve de la mañana a siete de la tarde [DOCJUR 2008, 193.3].

(8) a. Et fuese el fijo del labrador, et fizo leña, et tráxola a cuestas quanta le valió un maravedí [Calila, p. 326].

b. sin hablarse palabra, se pusieron a caballo y se apartaron [Quijote II, 30, p. 778].

c. A lo mejor llevaban la ropa del día anterior [Vuelo, p. 125].

Tal como he señalado supra, casos como los de (6) y (7) pueden explicarse a partir de un proceso metafórico o metonímico. De este modo, en el ejemplo ( $6 a)$, la meta locativa del verbo de movimiento está expresada en la FP- $a$ mediante una entidad humana: "a una mançeba". En (7a), la distancia entre una locación ("el logar o á el mucho oro") y otra ("monte Oreb") se mide en términos temporales ("a nueve días") y no mediante unidades de longitud propias para medir distancia entre dos lugares. Ahora bien, con independencia de la dificultad que entraña explicar las FP- $a$ con valores modales en términos de locación, aquéllas pueden ser consideradas también extensiones, metafóricas o metonímicas, en las que se expresan formas de alcanzar una meta. Así, en (8a) puede interpretarse la FP- $a$, "a cuestas", como el modo de lograr la meta, en este caso la manera de traer la leña.

En el Cuadro 2 puede verse la distribución diacrónica de los datos de acuerdo con la escala establecida. Una primera lectura horizontal de los datos del Cuadro 2 prueba que, con independencia del siglo analizado, el grupo de FP- $a$ con extensiones locativas es siempre la de mayor documentación en el corpus, por lo que podría interpretarse como el contexto base, antes incluso que el de locación estricta; sin embargo, la comparación diacrónica muestra, como se verá enseguida, otra perspectiva de análisis. 
Cuadro 2

Carácter locativo de la FP-a: escala de locatividad

\begin{tabular}{lllr}
\hline & Locativo & Extensión locativa & No locativo \\
\hline XIII & $21 \%(94 / 442)$ & $73 \%(322 / 442)$ & $6 \%(26 / 442)$ \\
XVII & $25 \%(105 / 427)$ & $60 \%(258 / 427)$ & $15 \%(64 / 427)$ \\
XXI & $21 \%(108 / 521)$ & $63 \%(327 / 521)$ & $16 \%(86 / 521)$ \\
ToTAL & $22 \%(307 / 1390)$ & $65 \%(907 / 1390)$ & $13 \%(176 / 1390)$ \\
\hline
\end{tabular}

En términos diacrónicos, además de la ya comentada estabilidad de la locación estricta y de su relativamente escasa documentación en el corpus, este cuadro arroja dos tipos de información general relevante: en primer lugar, prueba que la FP- $a$ mantiene, a lo largo de la historia del español, su naturaleza semántica mediante ampliaciones del significado locativo; en segundo, muestra que la FP- $a$ posee una baja aceptación de términos no locativos. En cuanto a la primera información, el término de la FP- $a$ se expresa de modo preferente por medio de una extensión locativa: $65 \%$ en total; esto es, en mucho más de la mitad de los datos del corpus general los valores léxico-semánticos humano y temporal codificados en la FP- $a$ pueden explicarse como extensiones del valor locativo original de la preposición $a$, tal como se observa en (6) y (7). Con respecto a la segunda información, puede verse en el Cuadro 2 que la FP- $a$ con el carácter no locativo es la de menor frecuencia: sólo $13 \%$ en total. Este hecho es en cierto modo previsible, puesto que implica un grado más avanzado en cuanto a los posibles procesos de abstracción sufridos por el significado básico locativo, y por ello el registro de casos como los de (8) es mucho menor y su generalización, más tardía.

En perspectiva diacrónica, resulta muy llamativo el incremento de las frases con carácter no locativo, ya que en el segundo corte cronológico aumentó su frecuencia de uso a más del doble, con respecto al siglo previo, e incluso aumentó un punto porcentual más en el último corte cronológico: $6 \%>15 \%>$ $16 \%$. El incremento de las FP- $a$ no locativas es estadísticamente significativo entre el siglo XIII y el siglo XVII. La comparación entre estos dos cortes arroja un estadístico $z=-4.404, p<.05$. Este cambio parece producirse a expensas de las FP- $a$ con extensio- 
nes locativas. Puede verse, en efecto, que entre el siglo xin y el siglo XVII estas últimas sufrieron una reducción considerable, de aproximadamente $13 \%$. Las FP- $a$ con extensiones humano o temporal pasaron de $73 \%$ a $60 \%$; se trata, igualmente, de un movimiento diacrónico estadísticamente significativo: $z=3.887$, $p<.05$. En el siglo XXI, las frecuencias de las FP- $a$ se mantienen estables en los tres grupos, aunque con mínimos movimientos si se comparan con las del siglo XVII.

En resumidas cuentas, el análisis diacrónico del valor locativo revela dos hechos de sumo interés para la teoría de cambio lingüístico: uno con respecto al alejamiento de los valores originales, en este caso observable en el proceso de deslocativización, y otro en cuanto al carácter conservador de las propiedades semánticas. Por lo que toca a la deslocativización, el corpus indica que, aun cuando la naturaleza locativa se mantiene latente en las FP- $a$, existe un proceso diacrónico de alejamiento o apertura del significado locativo estricto. Este cambio se hace evidente al contrastar cualitativamente el paso del valor locativo a contextos metafóricos o metonímicos, expresados mediante términos humanos o temporales, y, más evidente aún, al confrontar cuantitativamente la frecuencia de las FP- $a$ con extensión semántica con la frecuencia de las FP- $a$ de carácter no locativo. Se comprueba, efectivamente, que el decremento de las construcciones en las que subyace aún el valor semántico de locatividad favorece el aumento de las construcciones en las que ese significado es difícil de recuperar. Puede verse que la semántica de la FP- $a$ pasa de hacer referencia a locaciones concretas a expresar locaciones extensionales con las que se codifican entidades humanas, tiempo y modos o maneras de alcanzar una meta.

Por lo que respecta al carácter conservador, el corpus muestra que la FP- $a$ ha mantenido de modo estable, a lo largo de la historia del español, el valor locativo. La presencia constante de esta propiedad semántica refleja la naturaleza conservadora del cambio, no sólo porque el valor etimológico se ha mantenido de forma estricta durante siglos, sino porque además es posible encontrar indicios de este valor en los nuevos contextos funcionales en los que participa la FP- $a$, tal como sucede con las extensiones expresadas en las frases con las características humano y temporal. En efecto, si sumamos los porcentajes totales de la FP- $a$ con valor locativo $(22 \%)$ y de la FP- $a$ con extensión locativa (65\%), obtenemos que el $87 \%$ del total de los datos analizados guarda, en diverso grado, el significado de locación. 
El valor locativo en las FP-a en función de complemento locativo y complemento circunstancial

En este apartado analizo el comportamiento diacrónico de las FP- $a$ del corpus con función de complemento locativo y complemento circunstancial. Cabe precisar que, con el fin de reforzar el rasgo de locativo estricto, incluí dentro del grupo de complementos locativos todos los casos en los que el término de la preposición $a$ aludía a una localización ubicada en un espacio referencial, fuera ésta un complemento argumental o un adjunto. Esta decisión tiene como único objetivo unificar frases semánticamente afines; además, como mostraré, incluso añadiendo los locativos valenciales, el rasgo de locación decrece a lo largo de la historia del español.

Las razones que motivan el estudio particular de esta clase de FP- $a$ son dos, una cuantitativa y otra cualitativa: en cuanto a la primera, los complementos aquí analizados conforman uno de los grupos de mayor documentación en el corpus total. Más de un tercio del total de las FP- $a$ registradas, $38 \%$ aproximadamente, corresponde a complementos locativos y a complementos circunstanciales. En cuanto a la segunda, el estudio detallado de las FP- $a$ en estas dos funciones aporta datos de suma relevancia, ya que especifican directamente locaciones o bien circunstancias de la acción verbal, tales como el lugar, el tiempo, el modo, etc. Bajo esta perspectiva, los cambios experimentados en este tipo de complementos pueden dar un testimonio más puntual con respecto a la deslocativización de la FP- $a$. El propósito de este análisis es conocer si existe algún proceso interno de deslocativización en los contextos que muestran con mayor claridad los rasgos léxico-semánticos en los que participa la FP- $a$. Contrasto, a continuación, las ocurrencias de la FP- $a$ con función de complemento locativo, argumentales o no, con las FP- $a$ que cumplen la función de CC de tiempo y CC de modo.

Las FP- $a$ consideradas para el análisis de CC cubren los siguientes criterios: 1) codifican semánticamente circunstancias que precisan un evento; 2) los verbos no cambian su significado por tener o no un circunstancial; 3) los complementos pueden ser, en buena medida, susceptibles de omisión; 4) se pueden añadir con más facilidad que los complementos argumentales y 5) gozan de mayor libertad en el orden de la oración (cf. García-Miguel 1995, pp. 14-17, y Di Tullio 2014, 
pp. 115-117). En términos semánticos, la gramática tradicional ha determinado diversas clases de CC: modo, instrumento, medio, materia, compañía, lugar, tiempo, entre otros (RAEASALE 2009, §39.5). Las FP- $a$ del corpus que cumplen con la función de complemento locativo y CC se distribuyeron en tres clases semánticas: complemento locativo (9a), CC de tiempo $(9 b)$ y CC de modo $(9 c)$. En términos cuantitativos, de las $1390 \mathrm{FP}-a$ del corpus, 530 cumplen con la función de complemento locativo y CG.

(9) a. Judea cae all orient de Egipto [GEI, 2, p. 12]. nos acogimos a la Iglesia Mayor, donde nos amparamos del rigor de la justicia y dormimos lo necesario [Buscón, III, 10 , p. 255].

Tlacotzin quiso correr a los brazos de su madre [Ángeles, p. 30].

b. e será dado a las yentes pora escarnecer e pora açotar e pora crucifigar, e resucitará a tercer día [Mateo, p. 55]. al anochecer, su rocín y él se hallaron cansados y muertos de hambre [Quijote I, 2, p. 36].

Había visto a su mujer, Ameyali, saliendo de la choza con un fraile franciscano que a últimas fechas merodeaba mucho por esos rumbos [Ángeles, p. 31].

c. ¿Qué as esta noche que tornaste luego una vez en pos otra, aviendo fecho a tu guisa? [Calila, p. 185].

Yo, viendo que era batalla nabal y que no se había de hacer a caballo, comencé a apearme [Buscón, I, 2, p. 87].

a escondidas de papá repetía las oraciones [Ángeles, p. 32].

El Cuadro 3 presenta la distribución porcentual de las FP- $a$ registradas en el corpus, según la clase de complemento a la que se adscriben. Puede observarse que las FP- $a$ locativas son las de mayor documentación en cada corte cronológico y, en consecuencia, en la suma total del corpus: $56 \%$, frente a $23 \%$ para las FP- $a$ en función de CC de modo y $21 \%$ para las FP- $a$ en función de CG de tiempo. 


\section{Cuadro 3}

Semántica de las FP-a de complemento locativo, CC de tiempo y CC de modo ${ }^{25}$

\begin{tabular}{llll}
\hline & Lugar & Tiempo & Modo \\
\hline XIII & $73 \%(91 / 125)$ & $10 \%(13 / 125)$ & $17 \%(21 / 125)$ \\
XVII & $54 \%(100 / 187)$ & $17 \%(32 / 187)$ & $29 \%(55 / 187)$ \\
XXI & $48 \%(105 / 218)$ & $29 \%(64 / 218)$ & $23 \%(49 / 218)$ \\
TotAL & $56 \%(296 / 530)$ & $21 \%(109 / 530)$ & $23 \%(125 / 530)$ \\
\hline
\end{tabular}

En perspectiva diacrónica, los datos del Cuadro 3 arrojan información relevante con respecto al proceso de deslocativización experimentado por la FP- $a$ : primero, se confirma una disminución sostenida de contextos locativos, en contraste con el incremento de complementos temporales y modales y, segundo, se observa que la dinámica de cambio va, por un lado, de los contextos locativos a los modales y, por otro, de los locativos a los temporales. Tal comportamiento parece seguir una pauta distinta a la establecida desde la teoría, en la que suele señalarse que esta clase de cambios metafóricos se ordena linealmente en una escala que va del espacio al tiempo y, finalmente, al modo ${ }^{26}$.

Por lo que toca a la primera información, el Cuadro 3 revela, en concordancia con el apartado anterior, que las FP- $a$ en función de CG experimentaron un proceso de deslocativización. Puede verse que, en comparación con el aumento del resto de complementos, la documentación de locativos disminuye de modo constante en la diacronía establecida: $73 \%>54 \%>$ $48 \%$. El decremento más abrupto se presentó entre el siglo XIII y el siglo XVII, con una pérdida de 19 puntos porcentuales, que, en términos estadísticos, resulta significativo: $z=3.432, p .<.05$.

${ }^{25}$ En el Cuadro 3 se excluyen los casos en los que la FN término de $a$, siendo un locativo, cumple la función de OD: "E todos estos ríos corren por Troya e por Frigia, e por Tracia, que son tierras de la cibdad de Troya, e todas servién a la cibdad de Troya" (GEI, 1.286); o de modificador nominal: "este diario que va a ser al mismo tiempo un cuaderno de notas a pie de página" (Bartleby, p. 3).

26 Esta idea está desarrollada ampliamente en Heine, Claudi \& HüNNEMEYER 1991, pp. 48-53. 
En cambio, del siglo Xvir al xxi la FP- $a$ en función de complemento locativo perdió únicamente 6 puntos porcentuales.

Con respecto a la segunda información, el Cuadro 3 demuestra que el incremento cronológico de las FP- $a$ en función de CC de tiempo y de CC de modo se efectuó a expensas de las FP- $a$ en función de complemento locativo. La FP- $a$ en función de CC de tiempo experimentó un incremento diacrónico sostenido: $10 \%>17 \%>29 \%$; el segundo tipo, CC de modo, sufrió primero un incremento abrupto entre los siglos XIII y XVII: $17 \%>$ $29 \%$; y luego un decremento entre los siglos XVII y xxI: $29 \%>$ $23 \%$. La información anterior indica que el aumento más notable se presentó en los CG de modo y no en los CG de tiempo. De hecho, el incremento de las FP- $a$ en los contextos modales, entre el primer y segundo cortes cronológicos, resulta estadísticamente significativo: $z=-2.543, p<.05$. Cabría pensar, por tanto, que las FP- $a$ en función de CG de modo aumentaron a expensas de las FP- $a$ locativas y no de los CC de tiempo. En este caso el estadístico $z$ para los CC de tiempo, entre los siglos XIII y XVII, no resultó significativo: $z=-1.6537, p<.05$.

ANÁLISIS LÉXICO-SEMÁNTICO DEL CONTRASTE CONCRETO VS. ABSTRACTO EN LOS NOMBRES COMUNES TÉRMINO DE LA FP-A

El propósito de este apartado es mostrar si, en términos generales, la FP- $a$ experimentó un proceso de abstracción. Tal como señalé en la introducción, la abstracción es entendida aquí como un mecanismo diacrónico progresivo mediante el cual la preposición $a$ aceptó cada vez más FN con núcleos caracterizados por tener una semántica abstracta, en el sentido de 'no material'.

El valor concreto es uno de los significados léxicos esperados en la semántica de la FP- $a$, ya que está relacionado con el carácter locativo básico de la preposición $a$. Se espera que, a lo largo de la historia de la lengua, la FP- $a$ se haya desprendido paulatinamente de los contextos de naturaleza concreta y se haya dirigido hacia valores abstractos. Este proceso de abstracción es, como ya he señalado, un camino común en los fenómenos de cambio lingüístico, en el que los valores concretos se desgastan diacrónicamente y alcanzan contextos con niveles mayores de abstracción.

La información del corpus base de esta investigación indica que el núcleo gramatical del término de la preposición $a$ se 
expresa preferentemente mediante un nombre común: 1094 FP- $a$, esto es $92 \%$ del corpus, frente a $8 \%$ de frases con un nombre propio. Con base en esta información, y con el fin de no sesgar el análisis, estudio a continuación el contraste concretovs. abstracto, según se codifique uno u otro de estos valores únicamente en los nombres comunes término de la FP- $a$, y dejo fuera del estudio, por tanto, los casos con nombre propio.

El nombre común, como es sabido, conforma una categoría en la que se expresan nominales susceptibles de pertenecer a una determinada clase (RAE-ASALE 2009, §12.1c), de modo que cada uno de los términos nominales en ejemplos como los de (10), bestia, ave, vina, punto, casa, mujer, empleado, pertenece a una clase o especie con la que comparte ciertos rasgos, de ahí que se adscriban a la categoría de nombre común.

(10) et posieron et conpararon los más destos enxemplos $a$ las bestias salvajes et $a$ las aves [Calila, p. 89].

Dixo les: It a mi uinna [Mateo, p. 55]. y al punto daré la vuelta [Quijote I, 31, p. 314]. yo me vine a mi casa desde la plaza [Buscón, I, 2, p. 88]. Nunca ha sido difícil domar a una mujer salvaje [Vuelo, p. 271].

se podía ver también $a$ algunos empleados [Bartleby, p. 157].

En términos semánticos, el nombre común concreto se opone al nombre común abstracto en cuanto que el primero hace referencia a seres u objetos con existencia real, material o física (11a), mientras que el segundo alude a nombres carentes de realidad material, como acciones, procesos, cualidades (cf. RAE-ASALE 2009, §12.1i, y Bosque 1996, §1.5), tal y como se muestra en los ejemplos de (11b) (véase la "Introducción"):

(11) a. mandamos que la Semana Santa recojan a todos los poetas públicos y cantoneros [Buscón, II, 3, p. 148].

e aquí diz que los pidió él al pueblo e que lo fizo con ellos [GEI, 2, p. 863].

De pronto, su padre se llevó un dedo a los labios [Ángeles, p. 29].

$b$. Et estovieron así algunos días a su plazer, fasta que fueron comidos los dineros [Calila, p. 328].

para que sean condenados y castigados a la satisfaçión de la ymportançia de dicho robo [DLNE, 174, p. 460]. 
ha comentado que en esos seres que imitan la apariencia del hombre discreto y corriente habita, sin embargo, una turbadora tendencia a la negación del mundo [Bartleby, p. 14].

La distribución cronológica de los nombres comunes en cuanto a su naturaleza concreta o abstracta está expuesta en el Cuadro 4, en que puede verse una clara preferencia por los nombres comunes con el valor léxico-semántico concreto: $77 \%$ en total, frente a los nombres comunes abstractos: $23 \%$ en total.

\section{CuAdro 4}

Semántica del nombre común término de la FP-a: concreto $v s$. abstracto

\begin{tabular}{lll}
\hline & Concreto & Abstracto \\
\hline XIII & $85 \%(271 / 317)$ & $15 \%(46 / 317)$ \\
XVII & $84 \%(285 / 341)$ & $16 \%(56 / 341)$ \\
XXI & $65 \%(282 / 436)$ & $35 \%(154 / 436)$ \\
ToTAL & $77 \%(838 / 1094)$ & $23 \%(256 / 1094)$ \\
\hline
\end{tabular}

El Cuadro 4 arroja dos tipos de información relevante, uno general, en cuanto a la preeminencia del carácter concreto en los tres cortes cronológicos, y otro diacrónico, con respecto al avance del valor abstracto. Por lo que toca al primero, la FP- $a$ codifica en los tres siglos analizados mayoritariamente nombres comunes concretos. Este hecho está condicionado, como ya he señalado, por el significado locativo básico de la preposición $a$. El carácter de esta preposición, y por lo tanto de los contextos en los que participa la FP- $a$, es, sin duda, de naturaleza concreta, puesto que los referentes suelen ser espaciales, y por ello mejores candidatos para expresar cualidades materiales, en oposición a valores temporales o modales, en los que el referente no es material, sino de carácter nocional (cf. Pottier 1962 y Luraghi 2003, pp. 18-20).

El segundo tipo de información que aporta el Cuadro 4 comprueba que, en general, la FP- $a$ experimentó un proceso de cambio diacrónico dirigido hacia la abstracción; esto es, que sin importar los múltiples contextos funcionales en los que la 
FP- $a$ participa, ésta tiende a desplazarse hacia una semántica más abstracta. No obstante, existen matizaciones cronológicas: primero se documenta un período de estabilidad y luego un quiebre considerable. En cuanto al período de estabilidad, puede verse en el Cuadro 4 que tanto la FP- $a$ con nombre común concreto como la FP- $a$ con nombre común abstracto presentan una mínima diferencia entre el primer y segundo cortes cronológicos, hecho esperado en la hipótesis (cf. supra). En cuanto al quiebre, los datos del corpus indican que entre el siglo XVII y el siglo Xxi existe un período de inflexión; la FP- $a$ con nombre común concreto pierde 19 puntos porcentuales: $84 \%>65 \%$. En contraparte, las FP- $a$ con nombre común abstracto duplican con creces su frecuencia: pasan de $16 \%$ a $35 \%$; este cambio se da, sin duda, a expensas de las frases con término concreto.

El proceso diacrónico experimentado entre el segundo y tercer cortes cronológicos resulta estadísticamente significativo para ambos tipos de FP- $a$ : el decremento de frases con nombre común concreto que va del siglo XVII al XXI arroja un estadístico $z=5.886, p .<.05$; por su parte, el correspondiente incremento de frases con nombre común abstracto, para ese mismo período, arroja un estadístico $z=-5.886, p .<.05$. Estos resultados son relevantes, ya que el período álgido del proceso de abstracción de la FP- $a$ puede restringirse a los últimos trescientos años de la lengua española.

En suma, los datos de este análisis ponen de manifiesto, en primer lugar, un período de estabilidad en cuanto a los términos concretos de las FP- $a$ y, en segundo, una tendencia un tanto tardía, pero sustancial, hacia los términos abstractos.

\section{Discusión De LOS RESUltados}

Persistencia de los significados básicos

y ampliación de los nuevos contextos

El análisis de las variables anteriores confronta dos hechos generales: por un lado da cuenta de la estabilidad de los valores básicos en la semántica de la FP-a (locativo y concreto) y por otro demuestra que, gracias a tal continuidad, se han expandido contextos menos afines a los originales (no locativo y abstracto). En cuanto al valor locativo, los datos del corpus indican que la FP- $a$ ha mantenido una frecuencia diacrónica estable en los 
casos de locación estricta (s. XIII $21 \%>$ s. XVII $25 \%>$ s. XXI $21 \%$ ). La estabilidad cuantitativa de este valor semántico en los tres períodos analizados, allende la multiplicidad de contextos funcionales, corrobora que los contextos con localización ubicada en un espacio referencial (12a) están bien arraigados en la semántica de la preposición $a$. Desde esta perspectiva, la persistencia del significado etimológico -interpretada aquí como una consecuencia de gramaticalización (Hopper 1991, pp. 17-36) - confirma la hipótesis expuesta en este trabajo de que el valor locativo estricto sustenta los contextos innovadores en los que la locación es el resultado de una extensión metafórica o metonímica, tal como puede observarse en (12b). Este último hecho explicaría que los casos de FP- $a$ con el rasgo no locativo hayan aumentado a más del doble entre el siglo xiII y el siglo XVII: $6 \%>15 \%$, incremento que, como he señalado, resulta estadísticamente significativo $(z=-4.404, p<.05)$, por lo que el proceso de cambio semántico de deslocativización experimentado por la FP- $a$ puede asignarse a este período.

(12) a. non les serié mester de subir toda vía al monte de Sinaí [GEI, 2, p. 374].

Fuimos a verlo a su último refugio [Bartleby, p. 161].

$b$. Estonce salió Ihesús de Galilea, e fue a Iordán a Iohán quel bateasse [Mateo, p. 27].

de mal talante llegaron a sus animales [Quijote II, 30, p. 924].

a últimas fechas merodeaba mucho por esos rumbos [Ángeles, p. 31].

El aumento diacrónico de FN, término de $a$, con una semántica locativa extensional responde, en mi opinión, a un esquema de cambio que va del espacio físico al espacio mental. El cambio, en todo su conjunto, se produciría como una "cadena de significados"; esto es, un cambio que va del espacio físico al tiempo y después a dominios más abstractos, tales como la modalización ${ }^{27}$. En el caso de la preposición $a$, la cadena de significados resulta particularmente compleja debido a su amplitud funcional, aunque, por supuesto, existen propuestas de análisis: por ejemplo, las FN con función de OD (13a) y de OI (13b) introducidas por

27 Esta noción se ha utilizado, por ejemplo, en el tratamiento de las preposiciones inglesas, como en DIRVEN 1993. 
$a$ han sido explicadas como extensiones locativas que constituyen metas humanas, o bien los CC de tiempo, en los que el término preposicional se explica como una meta temporal (13c), o incluso los CC de modo, glosados como metas modales, en tanto que aluden a las maneras de alcanzar una meta (13d) (cf. Company y Flores 2014, p. 1318):

(13) a. Et mandó estonçes el león que prendiesen a Digna [Calila, p. 187].

b. A Duchamp siempre le gustó estar a la sombra [Bartleby, p. 160].

c. e resucitará a tercer día [Mateo, p. 55].

d. a pie o a caballo, siempre estaré al servicio vuestro [Quijote II, 30, p. 928].

Los resultados obtenidos en el análisis de esta investigación validan, en buena medida, la explicación del cambio semántico extensional. Obsérvese, para demostración de lo anterior, que la duplicación frecuencial de la FP- $a$ con carácter no locati$v o$, entre los siglos XIII y XVII $(6 \%>15 \%)$, es estadísticamente significativa $(z=-4.404, p<.05)$. Este aumento, además de confirmar el afianzamiento de las extensiones locativas en las FN término de $a$, sitúa como momento crítico del cambio el período establecido entre el primer y segundo cortes cronológicos. De manera más detallada, los datos aquí estudiados muestran que las extensiones semánticas se produjeron a favor de las FN con los rasgos humano o temporal. Corrobora este hecho el aumento, estadísticamente significativo $(z=3.887, p<.05)$, de la FP- $a$ con extensiones locativas entre los siglos XIII y XVII. De la misma forma, la hipótesis de un proceso de deslocativización se ve favorecida por los cambios que experimentó la FP- $a$ en función de complemento locativo y CC de modo. En cuanto al primer cambio, los complementos locativos disminuyeron notoriamente entre el siglo XIII y el siglo XVII $(73 \%>54 \%)$, pérdida estadísticamente significativa $(z=3.432, p .<.05)$. Esta información resulta relevante puesto que ubica el momento crítico del cambio entre el primer y segundo cortes cronológicos, hecho que confirma en parte la hipótesis propuesta en este trabajo, ya que se esperaba tener más locativos en el primer corte cronológico y menos en el segundo y tercero. En cuanto al segundo cambio, el incremento de los CC de modo resultó también estadísticamente significativo $(z=-2.543, p<.05)$ 
entre el primer y segundo cortes cronológicos, lo cual apoya el supuesto de la extensión semántica hacia contextos no locativos en esta etapa.

Por lo que toca al carácter concreto, los resultados de esta investigación revelan la preeminencia de FP- $a$ con este rasgo semántico en los tres cortes cronológicos. Este resultado confirma que la preposición $a$ se aviene mejor con términos concretos, puesto que se trata de un valor inherente a su naturaleza etimológica locativa. Cabe pensar, entonces, que la correspondencia entre los rasgos locación y concreto está relacionada con las funciones gramaticales en las que la FP- $a$ interviene: complementos locativos (14a), marca de OD, preferentemente para entidades animadas $(14 b)^{28}$, o bien, marca de OI, cercanos a las metas locativas (14c) (Baños Baños 2009, p. 199).

(14) $a$. et arrimóse a un árbol que estava en medio de la çibdat [Calila, p. 327].

el presidente les había pedido que lo acompañaran a la estancia La Unión [Vuelo, p. 127].

b. pondré a la princesa pacíficamente en su estado [Quijote I, 31, p. 390].

Pero la sola idea de entregar a su presa, para que otros se ufanaran de haber resuelto el caso, le revolvió las vísceras [Ángeles, p. 479].

c. tornó los treynta dineros de plata a los obispos [Mateo, p. 70].

e hizo que sirvieran a los músicos champán y papas fritas [Vuelo, p. 16].

Resulta sumamente llamativo que, a pesar de las restricciones semánticas que imponen los contextos funcionales, la FP- $a$ haya experimentado un decremento abrupto entre los siglos XVII y XXI $(84 \%>65 \%)$. Este comportamiento podría explicarse a partir del aumento, o inclusión, de otras funciones de la FP- $a$, encaminadas ya hacia una semántica abstracta, por ejemplo, los marcadores discursivos (a propósito, al contrario, a lo mejor), o bien,

${ }^{28}$ Como es bien sabido, la marca de OD en español se presenta preferentemente con entidades animadas; sin embargo, no son pocos los casos del español actual que registran la marca preposicional con entidades inanimadas, como en "calificó a la idea como «una payasada que seguramente cueste dinero y tiempo»". El ejemplo procede de Clarín (19/05/1997, Argentina), en el banco de datos CREA. Para un estudio sucinto de este fenómeno, véase КАвАТЕк 2016. 
otras funciones no analizadas en este trabajo, como las perífrasis (ir $+a+$ infinitivo) o los usos yusivos (; a comer!, ; a correr!), que podrían demostrar contextos con un grado más de abstracción.

Una de las hipótesis de esta investigación consistía, precisamente, en confirmar que el carácter concreto de la FP- $a$ es más frecuente en el primer corte cronológico, mientras que los contextos abstractos aumentan entre el segundo y tercer cortes. En efecto, la hipótesis se cumple y se ve reforzada estadísticamente, ya que el incremento de la FP- $a$ con nombre común abstracto, entre los siglos XVII y XXI, resultó significativo $(z=-5.886, p .<.05)$. El proceso aquí analizado parece seguir, con ciertos matices, la pauta de cambio señalada por Heine, Claudi \& Hünnemeyer (1991, p. 149), en la que se apunta que "una vez que las entidades tangibles y visibles reciben una interpretación espacial, pueden emplearse para expresar conceptos más abstractos". Con base en el supuesto anterior, podríamos decir entonces que después de que la FP- $a$ afianzó plenamente su empleo en contextos funcionales con entidades concretas -sustentados por la semántica locativa- generó, o amplió, rutinas de uso con entidades abstractas. El decremento del nombre común concreto entre los siglos XVII y XXI podría interpretarse como parte de un proceso de ampliación o apertura semántica a nuevos referentes cada vez más abstractos; esto es, con el paso del tiempo, allende la persistencia del valor concreto en todos los cortes cronológicos, la frecuencia de uso de FP- $a$ con valores semánticos alejados del significado básico se ha incrementado sucesivamente, tal como lo predecía la hipótesis de esta investigación.

Efecto dominó en el cambio léxico-semántico:

deslocativización > abstracción

La FP- $a$, como he venido mostrando a lo largo de este trabajo, ha padecido múltiples procesos que afectaron su naturaleza léxico-semántica. Por un lado, experimentó diacrónicamente un proceso de deslocativización, que en términos esquemáticos corresponde a FP- $a$ con el valor locativo estricto $>$ FP- $a$ con extensiones locativas humano/ temporales $>$ FP- $a$ de naturaleza modal. Por otro lado, la FN término de $a$ se flexibilizó semánticamente mediante un proceso de abstracción observable en la disminución diacrónica de términos concretos y un correspondiente aumento de términos abstractos. 
Los procesos de deslocativización y abstracción sufridos por la FP- $a$ constituyen un cambio léxico-semántico equiparable al efecto causado en la caída de fichas de dominó, en cuyo caso el impulso de una ficha empuja y produce el movimiento de otra. De este modo, fue necesario que el primer proceso, la deslocativización, se impulsara o extendiera a tal grado que afectara el segundo, la abstracción, y que, como desenlace, este último se activara o se impulsara con mayor fuerza. Los datos del corpus muestran, en efecto, que la deslocativización sucedió antes que la abstracción. Prueba de lo anterior es que las FP- $a$ de naturaleza no locativa, muy escasas en el siglo XIII, aumentaron significativamente en el siglo XVII $(z=-4.404, p<.05)$. En consecuencia, el término con nombre común abstracto, de baja frecuencia también en el siglo XIII, experimentó un aumento significativo entre los siglos XVII y XXI $(z=-5.886, p .<.05)$. El Gráfico 1 compara la distribución diacrónica de estos dos valores semánticos: no locativo y término abstracto. En el eje vertical se presenta el porcentaje registrado para cada una de las variables, en el apartado correspondiente en el que fueron analizadas; en el eje horizontal se indica el corte cronológico. La línea sólida corresponde al valor no locativo y la línea punteada al término abstracto.

\section{GRÁFICO 1}

Efecto dominó de la FP-a: valor no locativo y carácter abstracto ${ }^{29}$

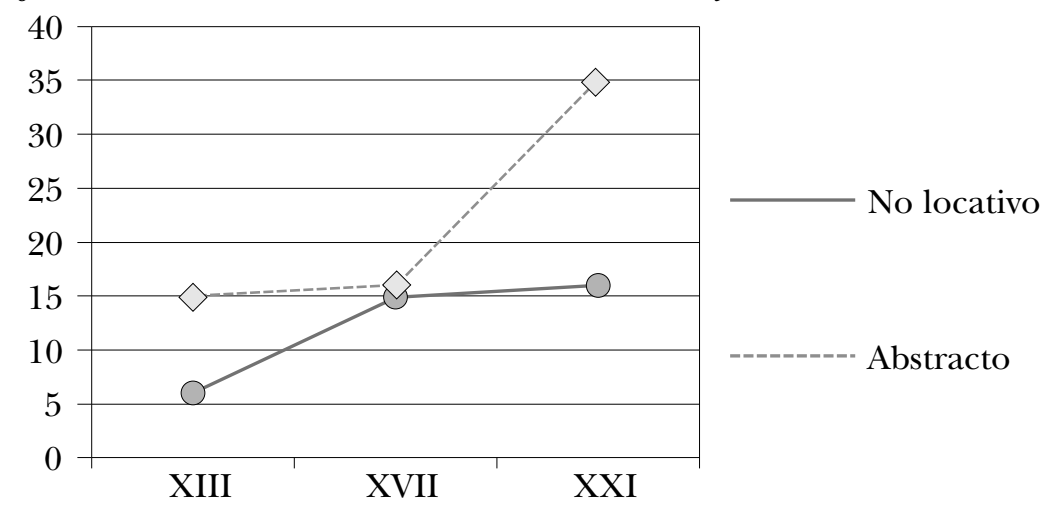

${ }^{29}$ Los porcentajes de este gráfico corresponden al Cuadro 2, para la variable no locativo, y al Cuadro 4, para la variable término abstracto, apartados "La naturaleza locativa general de la FP-a" y "Análisis léxico-semántico del contraste concreto vs. abstracto en los nombres comunes término de la FP-a", respectivamente. 
El Gráfico 1 permite observar con detalle el comportamiento de los dos procesos de cambio diacrónico objeto de este trabajo: primero, el aumento del término preposicional no locativo de la FP- $a$ y, segundo, el incremento del término abstracto. Con respecto al primer comportamiento, puede verse en el gráfico que el punto de inflexión en la ampliación cuantitativa de FP- $a$ no locativas se presenta entre el siglo XIII y el siglo XVII, de modo que es posible afirmar que la deslocativización se produce durante ese lapso. En cuanto al segundo comportamiento, el gráfico indica que la ampliación de FP- $a$ con términos abstractos se presenta de modo significativo una vez asentado el proceso de deslocativización; esto es, entre el siglo XVII y el siglo XXI.

En suma, el Gráfico 1 confirma que el incremento de las FP- $a$ con carácter no locativo parece haber sido un requerimiento previo necesario para la activación del término abstracto. Se trata, por tanto, de un proceso a modo de "efecto dominó", en el que el aumento de la FP- $a$ no locativa propició el aumento de términos abstractos. El carácter léxico-semántico etimológico expresado en la FP- $a$, como se puede observar, se modificó a lo largo de la historia de la lengua española en un proceso secuencial de deslocativización > abstracción.

\section{Conclusiones}

Los resultados generales que arroja el estudio diacrónico con respecto a los cambios léxico-semánticos experimentados por la FN, término de la preposición $a$, son dos: por un lado, los datos analizados demuestran que los valores asociados a los contextos etimológicos de la preposición $a$, el locativo y el concreto, han sido persistentes, aunque en grado diverso, a lo largo de la historia del español; por otro, el estudio documenta procesos de cambio en las rutinas semánticas de la $\mathrm{FN}$, término de $a$. Esta disociación se ajusta, sin duda, a los procesos habituales de cambio, caracterizados por un contraste de continuidades y discontinuidades.

En cuanto al valor locativo, el corpus de este trabajo indica que el valor locativo estricto ha persistido con una notoria estabilidad a lo largo de la historia del español, a pesar del gran número de casos de FP- $a$ con el rasgo locativo no estricto. Al margen de tal estabilidad, un análisis más detallado de los datos corrobora la ampliación, o alejamiento, de los valores originales mediante extensiones locativas, particularmente entre los siglos XIII y 
XVII. Este hecho, estadísticamente significativo, apoya la idea de un proceso de deslocativización. En suma, en la primera etapa del corpus, la semántica de la FP- $a$ pasa de contextos de locación estricta a locaciones extensionales. Por último, el análisis semántico de las FP- $a$ en función de complemento locativo, argumental o adjunto, frente a complementos temporales y modales, apunta a un decremento sostenido, estadísticamente significativo, de los contextos locativos a lo largo de los tres siglos analizados. Este comportamiento favoreció, sin duda, la presencia de los complementos de tiempo y modo a partir del siglo XVII, tal como se preveía en la hipótesis.

Por lo que toca al valor concreto, los resultados permiten confirmar, primero, un período estable del carácter concreto de las FP- $a$ entre los siglos XIII y XVII, seguido de un decremento considerable en el siglo xxI. Por el contrario, el valor abstracto se incrementó significativamente en el último período. Los datos analizados confirman, pues, un cambio en la semántica del término de la FP- $a$, interpretado aquí como un proceso de abstracción, predicho, también, en la hipótesis de esta investigación.

Finalmente, la concentración de los resultados de esta investigación sugiere firmemente la existencia de un proceso diacrónico de cambio léxico-semántico de la FP- $a$ a modo de "efecto dominó", que consistió en el decremento de FN, término de la preposición $a$, con carácter locativo a favor de FN con una naturaleza no locativa. El aumento de este último tipo de términos influyó directamente en la disminución del término concreto en beneficio del término abstracto.

\section{REFERENCIAS}

Alarcos Llorach, Emilio 2004 [1994]. Gramática de la lengua española, Espasa Calpe, Madrid.

Alcina Franch, Juan y José Manuel Blecua 1975. Gramática española, Ariel, Barcelona.

Baños Baños, José Miguel 2009. "Preposiciones”, en Sintaxis del latín clásico. Coord. J.M. Baños Baños, Liceus, Madrid.

Bassols de Climent, Mariano 1956. Sintaxis latina, Consejo Superior de Investigaciones Científicas, Madrid.

Bosque, Ignacio 1996. "Por qué determinados sustantivos no son sustantivos determinados", en El sustantivo sin determinación. La ausencia de determinante en la lengua española. Ed. Ignacio Bosque, Visor Libros, Madrid, pp. 13-119. 
BosQue, Ignacio 1999. "El nombre común”, en Gramática descriptiva de la lengua española. Eds. Ignacio Bosque y Violeta Demonte, Espasa, Madrid.

Bosque, Ignacio 2015. "Inner and outer prepositions with Spanish verbs of vertical movement", en Verb classes and lexical aspect. Eds. E. Barrajón et al., John Benjamins, Amsterdam, pp. 78-97.

Claudi, Ulrike \& Bernd Heine 1986. "On the metaphorical base of grammar”, Studies in Language 10, 2, pp. 297-335.

Company Company, Concepción 2003. "Transitivity and grammaticalization of object. The struggle of direct and indirect object in Spanish", en Romance objects. Transitivity in Romance languages. Ed. G. Fiorentino, Mouton de Gruyter, Berlin-New York, pp. 217-260.

Company Company, Concepción 2003a. "La gramaticalización en la historia del español”, en Gramaticalización y cambio sintáctico en la historia del español. Ed. Concepción Company, Universidad Nacional Autónoma de México, México, pp. 1-62.

Company Company, Concepción 2014. "Introducción”, en Sintaxis histórica de la lengua española. Tercera parte: Adverbios, preposiciones y conjunciones. Relaciones interoracionales. Dir. Concepción Company, Fondo de Cultura Económica-Universidad Nacional Autónoma de México, México, t. 1, pp. xvi-xviii.

Company Company, Concepción y Rodrigo Flores Dávila 2014. "La preposición a", en Sintaxis histórica de la lengua española. Tercera parte: Adverbios, preposiciones y conjunciones. Relaciones interoracionales. Dir. Concepción Company, Fondo de Cultura Económica-Universidad Nacional Autónoma de México, México, t. 2, pp. 1195-1340.

Crego García, María Victorina 2000. El complemento locativo en español. Los verbos de movimiento y su combinatoria sintáctico-semántica, Universidade de Santiago de Compostela, Santiago de Compostela.

Di Tullio, Ángela 2014 [2005], Manual de gramática del español, Waldhuter Editores, Buenos Aires.

Dirven, René 1993. "Dividing up physical and mental space into conceptual categories by means of English prepositions", en The semantics of prepositions. Ed. Cornelia Zelinsky-Wibbelt, Mouton de Gruyter, BerlinNew York, pp. 73-97.

Flores DÁvila, Rodrigo 2013. Gramaticalización de la preposición "a” con adyacencia de frase nominal, tesis, Universidad Nacional Autónoma de México, México.

García-Miguel, José María 1995. Transitividad y complementación preposicional en español, Universidade de Santiago de Compostela, Santiago de Compostela.

GeHrke, Berit 2008. Ps in motion. On the semantics and syntax of P elements and motion events, tesis, University of Utrecht LOT Dissertation Series, Utrecht.

Glare, Peter G. W. 2012 [1879]. Oxford Latin dictionary, Oxford University Press, Oxford.

Hanssen, Friedrich 1913. Gramática histórica de la lengua castellana, Max Niemeyer, Halle.

Haspelmath, Martin 1997. From space to time: Temporal adverbials in the world's languages, Lincom Europa, Newcastle. 
Heine, Bernd, Ulrike Claudi \& Friederike Hünnemeyer 1991. Grammaticalization: A conceptual framework, University of Chicago Press, Chicago.

Hopper, Paul 1991. "On some principles of grammaticalization", en Approaches to grammaticalization. Eds. Elizabeth C. Traugott \& Bernd Heine, John Benjamins, Amsterdam, pp. 17-36.

Hopper, Paul J. \& Elizabeth C. Traugott 2003 [1993]. Grammaticalization, Cambridge University Press, Cambridge.

KABATEK, JOHANNES 2016. "Wohin strebt die differentielle Objektmarkierung im Spanischen?”, Romanistisches Jahrbuch, 67, 1, pp. 211-239.

Kroch, Anthony 1989. "Reflexes of grammar in patterns of language change", Language Variation and Change, 1, 3, pp. 199-244.

Kühner, Raphael und Carl Stegmann 1914. Ausführliche Grammatik der lateinischen Sprache, t. 2, Hahnsche Buchhandlung, Hannover.

Kuteva, TANia \& Chris Sinha 1994. "Spatial and non-spatial uses of prepositions: Conceptual integrity across semantic domains", en Kognitive semantik/Cognitive Semantics. Ed. Monika Schwarz, Gunter Narr, Berlin, pp. 215-237.

Lakoff, George \& Mark Johnson 1980. Metaphors we live by, University of Chicago Press, Chicago.

Levinson, Stephen C. 2003. Space in language and cognition. Explorations in cognitive diversity, Cambridge University Press, Cambridge.

Levinson, Stephen C. \& David P. Wilkins 2006. "The background to the study of the language of space", en Grammars of space. Explorations in $\operatorname{cog}$ nitive diversity. Eds. Stephen C. Levinson \& David P. Wilkins, Cambridge University Press, Cambridge, pp. 1-22.

Luraghi, Silvia 2003. On the meaning of prepositions and cases, John Benjamins, Philadelphia-Amsterdam.

Martinet, André 1970 [1955]. Économie des changements phonétiques. Traité de phonologie diachronique, A. Francke, Berna.

Morera Pérez, Marcial 1988. Estructura semántica del sistema preposicional del español moderno y sus campos de uso, Cabildo Insular de Fuerteventura, Puerto del Rosario.

Pottier, Bernard 1955. "Espacio y tiempo en el sistema de las preposiciones", Boletín de Filología, 8, pp. 347-354.

PotTIER, Bernard 1962. Systématique des éléments de relation: étude de morphosyntaxe structurale Romane, Klincksieck, Paris.

RAE-ASALE 2009. Nueva Gramática de la lengua española, Espasa Libros, Madrid.

Stolz, Thomas 1992. Lokalkasussysteme. Aspekte einer strukturellen Dynamik, Gottfried Egert Verlag, Wilhelmsfeld.

Trujillo, Ramón 1971. "Notas para un estudio de las preposiciones españolas”, Thesaurus, 26, 2, pp. 234-279. 
Anexo. Corpus base

Calila = Calila e Dimna 1984 [1251]. Eds. Juan Manuel Cacho Blecua y María Jesús Lacarra, Castalia, Madrid.

DLE = Ramón Menéndez Pidal 1966 [1919]. Documentos lingüísticos de España. Reino de Castilla, Consejo Superior de Investigaciones Científicas, Madrid.

GEI = Alfonso X 2001 [1270], General estoria. Primera parte. Ed. Pedro Sánchez-Prieto Borja, Fundación José Antonio de Castro, Madrid.

Mateo = El Evangelio de San Mateo, según el manuscrito escurialense I.I.6. Texto, gramática, vocabulario. Ed. Thomas Montgomery, Real Academia Española, Madrid, 1962.

Buscón = Francisco de Quevedo 1990 [1626]. El Buscón. Ed. Pablo Jauralde Pou, Castalia, Madrid.

$D L N E=$ Concepción Company Company 1994. Documentos lingüísticos de la Nueva España. Altiplano central, Universidad Nacional Autónoma de México, México.

Quijote = Miguel de Cervantes 1996. Don Quijote de la Mancha, en Obras Completas. Eds. Francisco Sevilla Arroyo y Antonio Rey Hazas, Alianza Editorial-Centro de Estudios Cervantinos, Madrid.

Ángeles = EnriQue SERna 2004. Ángeles del abismo, Joaquín Mortiz, México. Bartleby = EnriQue Vila-Matas 2000. Bartleby y compañia, Anagrama, Barcelona.

DOCJUR = Documentos jurídicos del Tribunal de Zacatecas (2008-2009), México. Vuelo = Tomás Eloy Martínez 2002. El vuelo de la reina, Alfaguara, Madrid. 